Review began 10/07/2021 Review ended 10/11/2021 Published 10/14/2021

\section{() Copyright 2021}

Walia et al. This is an open access article distributed under the terms of the Creative Commons Attribution License CC-BY 4.0. which permits unrestricted use, distribution, and reproduction in any medium, provided the original author and source are credited.

\title{
A Systematic Review of the Use of St. John's Wort for Smoking Cessation in Adults
}

\author{
Namrata Walia ${ }^{1}$, Sandra Gonzalez ${ }^{1}$, Roger Zoorob ${ }^{1}$ \\ 1. Family and Community Medicine, Baylor College of Medicine, Houston, USA
}

Corresponding author: Namrata Walia, namrata.walia@bcm.edu

\begin{abstract}
St. John's wort (SJW) has been researched and clinically used for treating various psychiatric disorders, including depression. Few clinical trials have studied its use in smoking cessation. This systematic review provides comprehensive evidence of the studies conducted to date. Five databases were searched for randomized controlled trials (RCTs) that evaluated the effectiveness of SJW for smoking cessation in adults. The trials included the use of SJW alone, or along with nicotine replacement therapy, chromium, or behavioral therapies. The Preferred Reporting Items for Systematic Reviews and Meta-Analyses guidelines were used to report this systematic review. Overall, four RCTs met the eligibility criteria, and the risk of bias analysis was conducted using the Cochrane criteria. Abstinence, along with other physical symptoms, were measured as outcomes at the end of the follow-up period. Studies reported variable abstinence rates and a decrease in cravings at the end of 12-14 weeks. However, there was minimal to no difference reported between the intervention and placebo groups in all of the clinical trials. One of the studies reported minimal physical side effects. Overall, SJW was well tolerated. Quality analysis of the included studies showed low concerns in two studies while the other two studies showed high concerns in the risk of bias judgment. More clinical trials with larger sample sizes should be conducted in the future to evaluate the effectiveness of the use of SJW for smoking cessation.
\end{abstract}

Categories: Preventive Medicine, Public Health, Integrative/Complementary Medicine Keywords: systematic review, cigarette smoking, tobacco cessation, complementary alternative medicine, st. john's wort

\section{Introduction And Background}

Cigarette smoking is the leading cause of preventable disease and death in the United States [1]. Although the prevalence of adult smokers has declined in the past few decades, the estimate of current adult smokers increased from $13.7 \%$ adults in 2018 to $20.8 \%$ in 2019 [1,2]. Despite the known ill effects on health, a variety of combustible and non-combustible tobacco products are available in the United States. In 2019, around 50.6 million adults ( $20.8 \%$ of the US population) reported current use of any tobacco product. The majority of users reported using cigarettes, followed by e-cigarettes and cigars [1]. The Centers for Disease Control and Prevention (CDC) reported in 2015 that approximately two-thirds of cigarette smokers were interested in quitting smoking [3]. However, less than one in ten smokers were successful [3]. Evidence-based smoking cessation programs, including pharmacological and behavioral interventions, have successfully helped people to quit smoking [4-9]. These programs have shown to be cost-effective treatment options in clinical and community settings [10-14].

Complementary and alternative medicine has been shown to be a cost-effective treatment modality compared to conventional therapy alone in many medical conditions [15]. Hypericum perforatum, popularly called St. John's wort (SJW), was originally identified as an herb by Greek and Roman physicians [16]. In modern times, it has been extensively used in western countries such as the United States, the United Kingdom, and Germany. The herb has been reported to have antibacterial, antiviral, and anti-inflammatory properties [17]. It has been extensively studied in clinical trials as a treatment for pain [17], autism [18], major depressive disorder [19,20], and obsessive-compulsive disorder [21]. Recently, SJW has been studied as a treatment for smoking cessation. This systematic review provides comprehensive evidence from the literature and analyzes the consolidated results.

\section{Review}

\section{Methodology}

This review included randomized controlled trials (RCTs) that studied the effectiveness of SJW as a treatment modality for smoking cessation in adults aged 18 years and over. There was no limitation on the independent or combined use of SJW with other pharmacologic treatments. Non-randomized, quasiexperimental, and observational studies were excluded. Multiple databases, namely, Medline, Embase, Cochrane, Scopus, and PsychINFO, were used for a systematic search of published studies. The search methodology used keywords such as "St. John's wort," "Hypericum," “smoking cessation," "tobacco," and MeSH terms such as "Tobacco-related." Gray literature was searched using the Google search engine and no 


\section{Cureus}

additional relevant articles were found.

The data extraction and screening were conducted by a single reviewer. In case of uncertainty, the other two co-authors were consulted for a consensus-based discussion. The data were extracted using a predesigned data extraction form. The form included data on article name and author(s), journal information and publication date, sample size, eligibility criteria for studies, details on treatment and intervention groups, and results of the trials conducted. The quality of the trials was assessed using Cochrane Risk of Bias tool version 2 (ROB2) [22]. This tool assesses the trials based on five domains, namely, bias due to randomization process, deviations from intended interventions, missing outcome data, measurement of outcome, and selection of reported result. The overall score was reported as $\mathrm{H}$ (high risk of bias), $\mathrm{S}$ (some concerns), and $\mathrm{L}$ (low risk of bias).

\section{Results}

A total of 79 articles were found across all the databases searched. After removing duplicates and screening the abstracts, four studies met the eligibility criteria. The Preferred Reporting Items for Systematic Reviews and Meta-Analyses (PRISMA) guidelines were used for the reporting of this systematic review. Figure 1 shows the flow of the process in selecting the eligible studies.

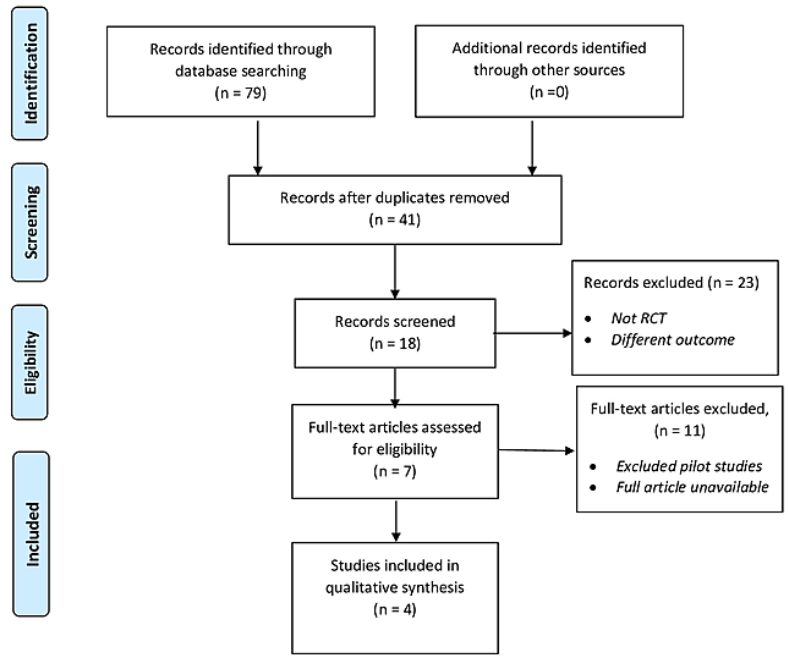

FIGURE 1: PRISMA flow diagram.

PRISMA: Preferred Reporting Items for Systematic Reviews and Meta-Analyses

Demographics and Sample Characteristics

Out of the four eligible studies, two were conducted in the United States, and the other two were conducted in the United Kingdom and Australia. Table 1 shows that the sample size for the studies ranged from 20 to 143 participants. Both male and female participants, over the age of 18, were included in the RCTs. Participants had a smoking history of 10 or more cigarettes per day; one of the studies required an additional five or more years of smoking and a prior quitting attempt as an eligibility criterion. 


\section{Cureus}

\begin{tabular}{|c|c|c|c|c|c|c|c|c|c|}
\hline Source & Country & $\begin{array}{l}\text { Sample } \\
\text { size }\end{array}$ & Age & $\begin{array}{l}\text { Smoking } \\
\text { history }\end{array}$ & Intervention & Duration & Outcome & $\begin{array}{l}\text { Outcome } \\
\text { measures }\end{array}$ & Result \\
\hline $\begin{array}{l}\text { Camfield } \\
\text { et al. } \\
\text { (2012) } \\
{[23]}\end{array}$ & Australia & 20 & $\begin{array}{l}18- \\
60 \\
\text { years }\end{array}$ & $\begin{array}{l}>5 \text { years. } \\
\text { Currently } \\
\text { smoking }>10 \\
\text { cigarettes/day; } \\
\text { at least one } \\
\text { prior attempt } \\
\text { at quitting }\end{array}$ & $\begin{array}{l}\text { SJW, NRT, } \\
\text { or both }\end{array}$ & $\begin{array}{l}14 \text { weeks; } \\
\text { Baseline: } \\
4 \text { weeks } \\
\text { prior to } \\
\text { quitting }\end{array}$ & $\begin{array}{l}\text { Neurocognitive } \\
\text { reaction time } \\
\text { and accuracy }\end{array}$ & $\begin{array}{l}\text { Spatial working } \\
\text { memory task; } \\
\text { steady-state probe } \\
\text { topography; } \\
\text { smokerlyser to } \\
\text { confirm abstinence }\end{array}$ & $\begin{array}{l}\text { The mean reduction in the number of cigarettes } \\
\text { smoked per week at week } 14 \text {, in comparison to } \\
\text { baseline, was } 55.93 \text { cigarettes for the SJW group, } \\
61.80 \text { cigarettes for the NRT group, and } 49.15 \\
\text { cigarettes for the SJW and NRT combined group. The } \\
\text { treatment groups showed similar efficacy in improving } \\
\text { cognitive effects }\end{array}$ \\
\hline $\begin{array}{l}\text { Sood et } \\
\text { al. } \\
(2010) \\
{[24]}\end{array}$ & $\begin{array}{l}\text { United } \\
\text { States }\end{array}$ & 118 & $\begin{array}{l}\text { Over } \\
18 \\
\text { years }\end{array}$ & $\begin{array}{l}10 \text { cigarettes } \\
\text { per day in the } \\
\text { past year }\end{array}$ & $\begin{array}{l}300 \mathrm{mg}, 600 \\
\mathrm{mg} \text {, or } \\
\text { placebo } \\
\text { three times } \\
\text { a day plus } \\
\text { behavioral } \\
\text { intervention }\end{array}$ & $\begin{array}{l}12 \text { weeks } \\
\text { (additional } \\
12 \text { weeks } \\
\text { follow-up) }\end{array}$ & $\begin{array}{l}\text { Abstinence } \\
\text { and craving }\end{array}$ & $\begin{array}{l}\text { Fagerstrom test for } \\
\text { nicotine } \\
\text { dependence; CES- } \\
\text { D scale; } \\
\text { contemplation } \\
\text { ladder to measure } \\
\text { readiness to quit; } \\
\text { MNWS with } \\
\text { smoking diary; } \\
\text { Beck Depression } \\
\text { Inventory, second } \\
\text { edition, CAGE, and } \\
\text { DAST-20 }\end{array}$ & $\begin{array}{l}\text { The mean cigarettes per day did not differ significantly } \\
\text { between groups } 8.77 .2(n=15) \text { placebo; } 9.59 .3(n= \\
12) \text { for the } 300 \mathrm{mg} \text { group; and } 9.56 .4(n=16) \text { for the } \\
600 \mathrm{mg} \text { group. Nicotine withdrawal and craving were } \\
\text { both observed to decrease significantly with time } \\
\text { (withdrawal:estimate }=-0.019 \text { per day, } \mathrm{SE}=0.008, \mathrm{p} \\
=0.016 ; \text { craving:estimate }=-0.031 \text { per day, } \mathrm{SE}= \\
0.01, \mathrm{p}=0.018) . \text { However, no significant differences } \\
\text { were observed in abstinence rates at } 12 \text { and } 24 \\
\text { weeks between SJW dose groups and placebo }\end{array}$ \\
\hline $\begin{array}{l}\text { Parsons } \\
\text { et al. } \\
\text { (2009) } \\
{[25]}\end{array}$ & $\begin{array}{l}\text { United } \\
\text { Kingdom }\end{array}$ & 143 & $\begin{array}{l}\text { Over } \\
18 \\
\text { years }\end{array}$ & $\begin{array}{l}>10 \text { cigarettes } \\
\text { per day }\end{array}$ & $\begin{array}{l}900 \mathrm{mg} \mathrm{SJW} \\
\text { and } 400 \mathrm{~m} \\
\text { chromium; } \\
\text { and placebo }\end{array}$ & $\begin{array}{l}14 \text { weeks; } \\
\text { treatment } \\
\text { started } 2 \\
\text { weeks } \\
\text { before }\end{array}$ & $\begin{array}{l}\text { Abstinence } \\
\text { and change in } \\
\text { weight }\end{array}$ & $\begin{array}{l}\text { MPSS-C score } \\
\text { (urge to smoke), } \\
\text { MPSS-M score } \\
\text { (mood changes), } \\
\text { MPSS-P score } \\
\text { (physical } \\
\text { symptoms) }\end{array}$ & $\begin{array}{l}\text { Participants on active SJW }(8.5 \%) \text { and placebo } \\
(12.5 \%) \text { achieved prolonged abstinence at } 4 \text { weeks, } \\
\text { with an OR }(95 \% \mathrm{Cl}) \text { of } 0.65(0.22-1.92) \text {. At } 6 \text { months } \\
\text { SJW active }(4.2 \%) \text { and SJW placebo }(8.3 \%) \\
\text { participants were still abstinent, with an OR of } 0.49 \\
(0.12-2.02) \text {. The mean difference in weight gain } \\
\text { between active chromium and placebo was }-0.81 \mathrm{~kg} \\
(-3.79 \text { to } 2.18) \text { at } 4 \text { weeks and }-3.88 \mathrm{~kg}(-12.13 \text { to } \\
4.38) \text { at } 6 \text { months }\end{array}$ \\
\hline $\begin{array}{l}\text { Lawvere } \\
\text { et al. } \\
\text { (2006) } \\
{[26]}\end{array}$ & $\begin{array}{l}\text { United } \\
\text { States }\end{array}$ & 37 & $\begin{array}{l}18- \\
65 \\
\text { years }\end{array}$ & $\begin{array}{l}10 \\
\text { cigarettes/day }\end{array}$ & $\begin{array}{l}\text { SJW } 450 \\
\text { mg plus } \\
\text { cessation } \\
\text { counseling } \\
\text { messages }\end{array}$ & 12 weeks & $\begin{array}{l}\text { Abstinence, } \\
\text { weight } \\
\text { change, and } \\
\text { physical } \\
\text { changes }\end{array}$ & $\begin{array}{l}\text { Carbon monoxide } \\
\text { testing; Shiffman- } \\
\text { Jarvik for } \\
\text { withdrawal } \\
\text { symptom scale; } \\
\text { anxiety and } \\
\text { depression scale }\end{array}$ & $\begin{array}{l}\text { A quit rate of } 37.5 \%(95 \% \text { Cl: } 21.1 \%, 57.5 \%) \text { with nine } \\
\text { of the original } 37 \text { subjects who started taking SJW } \\
\text { smoke-free at } 12 \text { weeks. No significant change in } \\
\text { weight was noted. Use of SJW was generally well } \\
\text { tolerated }\end{array}$ \\
\hline
\end{tabular}

\section{TABLE 1: Study characteristics and outcomes of eligible studies.}

SJW: St. John's Wort; NRT: nicotine replacement therapy; CES-D: Center for Epidemiologic Studies Depression; MNWS: Minnesota Tobacco Withdrawal Scale; DAST-20: Drug Abuse Screen Test 20; CAGE: Cut down, Annoyed, Guilty, and Eye-opener; MPSS: Mood and Physical Symptoms Scale; OR: odds ratio; $\mathrm{Cl}$ : confidence interval; $\mathrm{SE}$ : standard error

Intervention Details

Table 1 describes the intervention and placebo of the selected studies. The studies investigated the effectiveness of SJW alone or in combination with nicotine replacement therapy (NRT), chromium, behavioral therapy, and cessation counseling messages. The studies followed their participants for 12-14 weeks until the primary data collection timepoint. One of the studies by Sood et al. [23] followed the participants for an additional 12 weeks for collecting secondary data. Table 1 lists all the varied outcome measures used.

Outcomes

Camfield et al. [24] conducted an RCT to evaluate neurocognitive effects (memory function test for reaction time and accuracy) during the use of SJW for smoking cessation. The authors used spatial working memory task, steady-state probe topography, and smokerlyser to confirm abstinence from smoking. The mean reduction in the number of cigarettes smoked per week at week 14, in comparison to baseline, was 55.93 
cigarettes for the SJW group, 61.80 cigarettes for the NRT group, and 49.15 cigarettes for the SJW and NRT combined group. The interaction between treatment groups (SJW, NRT, or NRT + SJW) and study visit (baseline vs. retest) $(\mathrm{F}(2,17)=1.674 ; \mathrm{p}>0.05)$ and between treatment groups and time $(\mathrm{F}(2,17)=0.415 ; \mathrm{p}>$ 0.05 ) were found to be non-significant. However, pairwise comparisons revealed that, at retest, the reaction time was faster for the SJW group compared to the NRT group $(\mathrm{p}=0.116)$. The authors interpreted that lack of results (or lack of difference in groups) could mean similar efficacy of the treatment groups.

Sood et al. [23] examined the efficacy of SJW for smoking cessation using two different oral doses (300 or 600 $\mathrm{mg}$ ). The authors used the Fagerstrom test for nicotine dependence, the Center for Epidemiologic Studies Depression Scale (CES-D), the contemplation ladder to measure readiness to quit, the Minnesota Tobacco Withdrawal Scale (MNWS) with smoking diary, the Beck Depression Inventory, Cut down, Annoyed, Guilty, and Eye-opener (CAGE), and Drug Abuse Screen Test 20 (DAST-20). The mean cigarettes smoked per day did not differ significantly between groups 8.77.2 $(\mathrm{n}=15)$ and placebo; $9.59 .3(\mathrm{n}=12)$ for the $300 \mathrm{mg}$ group and 9.56.4 $(\mathrm{n}=16)$ for the $600 \mathrm{mg}$ group. Nicotine withdrawal and craving were both observed to decrease significantly with time (withdrawal:estimate $=-0.019$ per day, standard error $[S E]=0.008, p=0.016$; craving:estimate $=-0.031$ per day, $\mathrm{SE}=0.01, \mathrm{p}=0.018$ ). Using the intention-to-treat analysis, no significant differences were observed in abstinence rates at 12 and 24 weeks between SJW dose groups and placebo. SJW did not attenuate withdrawal symptoms among abstinent subjects. However, no significant side-effects were noted with SJW.

Parsons et al. [25] examined the combined use of SJW and chromium to aid in smoking cessation and prevent associated weight gain. The authors used the Mood and Physical Symptoms Scale (MPSS)-C score to measure urge to smoke, MPSS-M score for mood changes, and MPSS-P score to measure physical symptoms such as constipation, mouth sores, and sore throat. Participants on active SJW (8.5\%) and on placebo (12.5\%) achieved prolonged abstinence at four weeks, with an odds ratio (OR) (95\% confidence interval [CI]) of 0.65 (0.22-1.92). At six months, SJW active (4.2\%) and SJW placebo (8.3\%) participants were still abstinent, with an OR of $0.49(0.12-2.02)$. The mean difference in weight gain between active chromium and placebo was $-0.81 \mathrm{~kg}$ ( -3.79 to 2.18 ) at four weeks and $-3.88 \mathrm{~kg}(-12.13$ to 4.38$)$ at six months. There were no significant differences in urges to smoke or tobacco withdrawal symptoms. However, it was safe and well tolerated.

Lawvere et al. [26] examined the feasibility and efficacy of SJW for smoking cessation. The authors used carbon monoxide (CO) testing, Shiffman-Jarvik for withdrawal symptom scale, and anxiety and depression scale. The 12 -week quit rate was nine participants or $37.5 \%$ (95\% CI: $21.1 \%, 57.5 \%)$; 13 (54\%) participants were smoke-free at the three-week visit. No significant change in weight was noted. Participants reported physical symptoms such as a change in bowel movements (8.8\%), sensitivity to light (5.9\%), constipation (5.9\%), abdominal pain (2.9\%), dizziness (2.9\%), and fatigue (2.9\%). Overall, the use of SJW was well tolerated.

Risk of Bias Assessment

Cochrane Risk of Bias tool for randomized trials [22] was used to assess the risk of bias and quality of trials. Table 2 shows that two out of the four eligible studies showed low concerns, while the other two studies showed high concerns regarding the risk of bias judgment. Two studies did not have information if the outcome assessors were blinded from the randomization. This led to high concerns regarding the risk of bias. The studies also did not address or change the statistical analysis plan due to missing data. 


\section{Cureus}

\begin{tabular}{|c|c|c|c|c|}
\hline & \multicolumn{4}{|l|}{ Studies } \\
\hline & $\begin{array}{l}\text { Camfield et al. } \\
\text { [23] }\end{array}$ & $\begin{array}{l}\text { Sood et al. } \\
\text { [24] }\end{array}$ & $\begin{array}{l}\text { Parsons et al. } \\
\text { [25] }\end{array}$ & $\begin{array}{l}\text { Lawvere et al. } \\
{[26]}\end{array}$ \\
\hline Risk of bias arising from randomization process & Low & Low & Low & Low \\
\hline $\begin{array}{l}\text { Risk of bias due to intended intervention (effect of assignment to } \\
\text { intervention) }\end{array}$ & Low & Low & Low & Low \\
\hline $\begin{array}{l}\text { Risk of bias due to intended intervention (effect of adhering to } \\
\text { intervention) }\end{array}$ & Low & Low & Low & Low \\
\hline Risk of bias due to missing outcome data & Some concerns & Low & Low & Low \\
\hline Risk of bias in measurement of the outcome & High & Low & High & Low \\
\hline Risk of bias in selection of the reported result & Low & Low & Some concerns & Low \\
\hline Overall risk of bias & High & Low & High & Low \\
\hline
\end{tabular}

TABLE 2: Risk of bias judgment (low, some concerns, high).

\section{Discussion}

To our knowledge, this is the first systematic review to analyze the efficacy of the use of SJW for smoking cessation. The studies included in this review used a combination of SJW with NRT, behavioral interventions, or chromium to curbing weight gain caused by smoking cessation. The authors showed a reduction in the number of mean cigarettes, but no significant difference was reported between the different groups or placebo. The groups showed similar effects on their respective outcomes, including cognitive effects, changes in weight or physical symptoms, and craving. The results of this systematic review of four RCTs, with a total of 318 participants, did not provide sufficient evidence for using SJW for smoking cessation. However, further randomized trials with larger sample sizes should be conducted in the future.

The safety profile of complementary and alternative medicine has been well studied and reported. Most types of complementary and alternative medicine are safe to use, with minimal to no side effects. SJW, in particular, has been shown to be safe and effective in patients experiencing symptoms of depression. In the clinical studies included in this review, SJW was well tolerated, and no significant side effects were experienced by patients. However, the participants using SJW in the studies reported minor physical side effects including headaches, nausea and vomiting, diarrhea, fatigue, dizziness, dry mouth, and insomnia at least once during the study period.

Smoking cessation attempts have been associated with symptoms such as anxiety, depression, and mood changes [27]. The clinical efficacy of the use of SJW for psychiatric disorders such as major depressive disorders has been previously reported in the literature $[19,20]$. Because smoking and depression have common neurobiological mechanisms, the researchers and clinicians assumed a similar effect of SJW on smoking cessation. However, the RCTs conducted to date did not show any difference in the use of SJW and placebo for aiding smoking cessation.

Participant treatment adherence and drop-outs are an issue for interventional clinical studies for addictive substances. The social and biological phenomenon behind the addiction of smoking and the chronic use of tobacco induces structural and functional changes in the brain. The re-wiring or re-educating the brain during smoking cessation attempts requires psychosocial support in addition to pharmacotherapy. The lack of such interventions in a clinical study determining the efficacy of a treatment modality could provide inconclusive results. An integrative approach including interventions targeting the psychosocial factors is recommended to test the treatment in a real-life environment.

\section{Study limitations}

A meta-analysis could not be conducted due to the high risk of bias in most studies. Moreover, the studies used different statistical parameters to report their results, due to which a meta-analysis was not feasible. Lastly, RCTs are not always the most suitable study design. Future systematic reviews should be conducted including cross-sectional studies to evaluate the use and efficacy of SJW as a smoking cessation aid.

\section{Conclusions}

This review demonstrated the potential of SJW as an adjunct treatment modality for smoking cessation. 
However, the small number of RCTs reported in the literature, and included in the systematic review, failed to provide evidence in favor of the effectiveness of SJW for smoking cessation. Further clinical trials with larger sample sizes, possibly conducted with a different study design, or high-quality trials of intervention should be conducted in the future to evaluate the effectiveness of the use of SJW for smoking cessation.

\section{Additional Information \\ Disclosures}

Conflicts of interest: In compliance with the ICMJE uniform disclosure form, all authors declare the following: Payment/services info: This work was supported by the Department of Health and Human Services, Health Resources and Services Administration, Grant number T32 HP10031. Financial relationships: All authors have declared that they have no financial relationships at present or within the previous three years with any organizations that might have an interest in the submitted work. Other relationships: All authors have declared that there are no other relationships or activities that could appear to have influenced the submitted work.

\section{References}

1. Cornelius ME, Wang TW, Jamal A, Loretan CG, Neff LJ: Tobacco product use among adults - United States, 2019. MMWR Morb Mortal Wkly Rep. 2020, 69:1736-42. 10.15585/mmwr.mm6946a4

2. Creamer MR, Wang TW, Babb S, et al.: Tobacco product use and cessation indicators among adults - United States, 2018. MMWR Morb Mortal Wkly Rep. 2019, 68:1013-9. 10.15585/mmwr.mm6845a2

3. Babb S, Malarcher A, Schauer G, Asman K, Jamal A: Quitting smoking among adults - United States, 20002015. MMWR Morb Mortal Wkly Rep. 2017, 65:1457-64. 10.15585/mmwr.mm6552a1

4. Barnes J, McRobbie H, Dong CY, Walker N, Hartmann-Boyce J: Hypnotherapy for smoking cessation . Cochrane Database Syst Rev. 2019, 6:CD001008. 10.1002/14651858.CD001008.pub3

5. Hartmann-Boyce J, Chepkin SC, Ye W, Bullen C, Lancaster T: Nicotine replacement therapy versus control for smoking cessation. Cochrane Database Syst Rev. 2018, 5:CD000146. 10.1002/14651858.CD000146.pub5

6. Lancaster T, Stead LF: Individual behavioural counselling for smoking cessation . Cochrane Database Syst Rev. 2017, 3:CD001292. 10.1002/14651858.CD001292.pub3

7. Lindson N, Klemperer E, Hong B, Ordóñez-Mena JM, Aveyard P: Smoking reduction interventions for smoking cessation. Cochrane Database Syst Rev. 2019, 9:CD013183. 10.1002/14651858.CD013183.pub2

8. Lindson N, Thompson TP, Ferrey A, Lambert JD, Aveyard P: Motivational interviewing for smoking cessation. Cochrane Database Syst Rev. 2019, 7:CD006936. 10.1002/14651858.CD006936.pub4

9. Malas M, van der Tempel J, Schwartz R, et al.: Electronic cigarettes for smoking cessation: a systematic review. Nicotine Tob Res. 2016, 18:1926-36. 10.1093/ntr/ntw119

10. Drouin O, Sato R, Drehmer JE, Nabi-Burza E, Hipple Walters B, Winickoff JP, Levy DE: Cost-effectiveness of a smoking cessation intervention for parents in pediatric primary care. JAMA Netw Open. 2021, 4:e213927. 10.1001/jamanetworkopen.2021.3927

11. Reisinger SA, Kamel S, Seiber E, Klein EG, Paskett ED, Wewers ME: Cost-effectiveness of community-based tobacco dependence treatment interventions: initial findings of a systematic review. Prev Chronic Dis. 2019, 16:E161. 10.5888/pcd16.190232

12. Salloum RG, LeLaurin JH, Dallery J, Childs K, Huo J, Shenkman EA, Warren GW: Cost evaluation of tobacco control interventions in clinical settings: a systematic review. Prev Med. 2021, 146:106469. 10.1016/j.ypmed.2021.106469

13. Shearer J, Shanahan M: Cost effectiveness analysis of smoking cessation interventions . Aust N Z J Public Health. 2006, 30:428-34. 10.1111/j.1467-842x.2006.tb00458.x

14. Barnett PG, Wong W, Hall S: The cost-effectiveness of a smoking cessation program for out-patients in treatment for depression. Addiction. 2008, 103:834-40. 10.1111/j.1360-0443.2008.02167.x

15. Herman PM, Craig BM, Caspi O: Is complementary and alternative medicine (CAM) cost-effective? A systematic review. BMC Complement Altern Med. 2005, 5:11. 10.1186/1472-6882-5-11

16. Istikoglou CI, Mavreas V, Geroulanos G: History and therapeutic properties of Hypericum perforatum from antiquity until today. Psychiatriki. 2010, 21:332-8.

17. Galeotti N: Hypericum perforatum (St John's wort) beyond depression: a therapeutic perspective for pain conditions. J Ethnopharmacol. 2017, 200:136-46. 10.1016/j.jep.2017.02.016

18. Niederhofer H: St John's Wort treating patients with autistic disorder . Phytother Res. 2009, 23:1521-3. 10.1002/ptr.2580

19. Fava M, Alpert J, Nierenberg AA, et al.: A double-blind, randomized trial of St John's wort, fluoxetine, and placebo in major depressive disorder. J Clin Psychopharmacol. 2005, 25:441-7. 10.1097/01.jcp.0000178416.60426.29

20. Sarris J, Fava M, Schweitzer I, Mischoulon D: St John's wort (Hypericum perforatum) versus sertraline and placebo in major depressive disorder: continuation data from a 26-week RCT. Pharmacopsychiatry. 2012, 45:275-8. 10.1055/s-0032-1306348

21. Kobak KA, Taylor LV, Bystritsky A, et al.: St John's wort versus placebo in obsessive-compulsive disorder: results from a double-blind study. Int Clin Psychopharmacol. 2005, 20:299-304. 10.1097/00004850200511000-00003

22. Sterne JA, Savović J, Page MJ, et al.: RoB 2: a revised tool for assessing risk of bias in randomised trials . BMJ. 2019, 366:14898. 10.1136/bmj.14898

23. Camfield DA, Scholey AB, Pipingas A, et al.: The neurocognitive effects of Hypericum perforatum Special Extract (Ze 117) during smoking cessation. Phytother Res. 2013, 27:1605-13. 10.1002/ptr.4909

24. Sood A, Ebbert JO, Prasad K, Croghan IT, Bauer B, Schroeder DR: A randomized clinical trial of St. John's wort for smoking cessation. J Altern Complement Med. 2010, 16:761-7. 10.1089/acm.2009.0445 


\section{Cureus}

25. Parsons A, Ingram J, Inglis J, et al.: A proof of concept randomised placebo controlled factorial trial to examine the efficacy of St John's wort for smoking cessation and chromium to prevent weight gain on smoking cessation. Drug Alcohol Depend. 2009, 102:116-22. 10.1016/j.drugalcdep.2009.02.006

26. Lawvere S, Mahoney MC, Cummings KM, Kepner JL, Hyland A, Lawrence DD, Murphy JM: A phase II study of St. John's Wort for smoking cessation. Complement Ther Med. 2006, 14:175-84. 10.1016/j.ctim.2006.01.007

27. Taylor G, Aveyard P, Meer RV, Toze D, Stuijfzand B, Kessler D, Munafò M: Impact of variation in functions and delivery on the effectiveness of behavioural and mood management interventions for smoking cessation in people with depression: protocol for a systematic review and meta-analysis. BMJ Open. 2017, 7:e018617. 10.1136/bmjopen-2017-018617 